NIST

PUBLICATIONS

NISTIR 90-3936

\title{
EFFECT OF NOBLE GAS MIXTURES ON THE PERFORMANCE OF REGENERATIVE-TYPE CRYOCOOLERS ANALYTICAL ESTIMATE
}

David E. Daney 
NATIONAL INSTTUTE OF STMNDARDS \& TECHNOLOGI

Resestch Informatin Center

Gaithersburg, MD 20899 


\section{NISTIR 90-3936}

\section{EFFECT OF NOBLE GAS MIXTURES ON THE PERFORMANCE OF REGENERATIVE-TYPE CRYOCOOLERS ANALYTICAL ESTIMATE}

\section{David E. Daney}

Chemical Engineering Science Division

Center for Chemical Technology

National Measurement Laboratory

National Institute of Standards and Technology

Boulder, Colorado 80303-3328

September 1990

Sponsored by

Air Force Space Technology Center

Kirtland Air Force Base, New Mexico 87117-6008

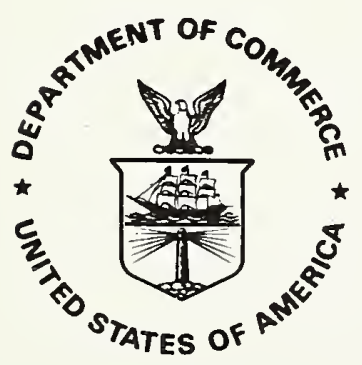

U.S. DEPARTMENT OF COMMERCE, Robert A. Mosbacher, Secretary NATIONAL INSTITUTE OF STANDARDS AND TECHNOLOGY, John W. Lyons, Director 



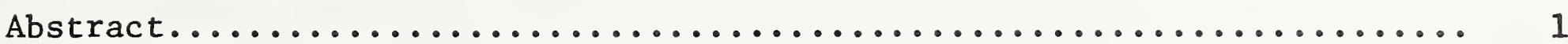

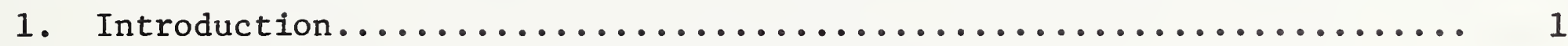

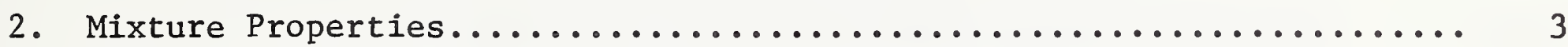

3. Dependence of Heat Transfer on Prandt Number................. 10

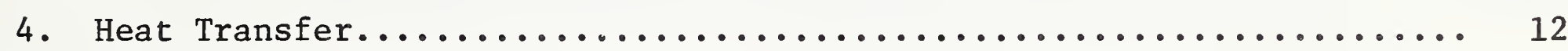

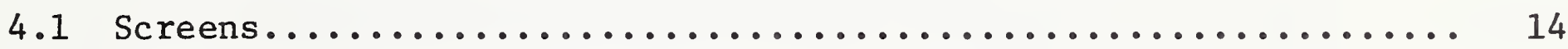

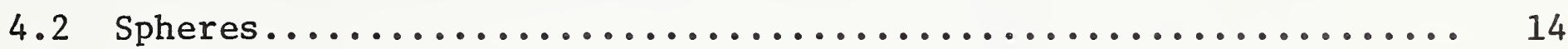

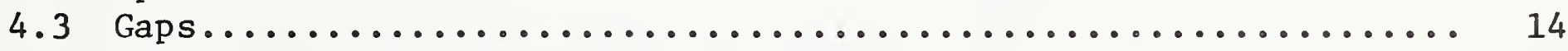

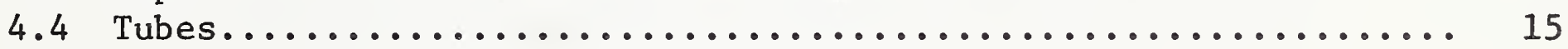

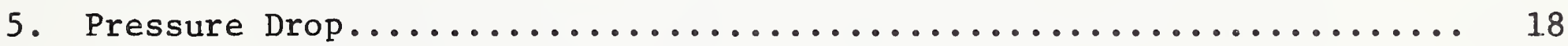

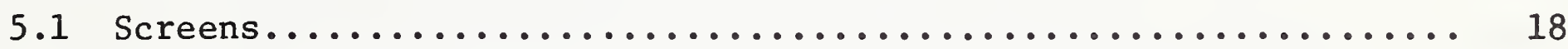

5.2 Randomly Packed Spheres............................. 19

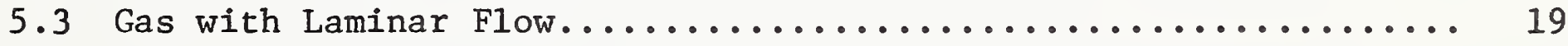

5.4 Tubes With Turbulent Flow.......................... 19

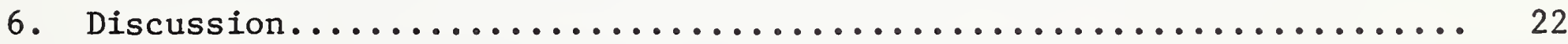

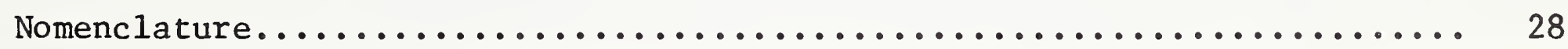

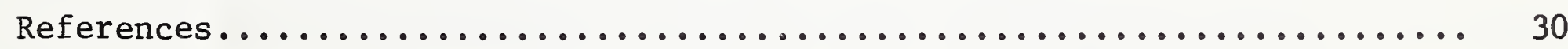


Figure 1. Transport properties of helium-krypton mixtures.

Figure 2. Thermal conductivity of helium-argon mixtures.

Figure 3. Dilute gas Prandtl number for $\mathrm{He}-\mathrm{Ar}$ and $\mathrm{He}-\mathrm{Kr}$ calculated from mixing rules.

Figure 4. Dilute gas thermal conductivity for He-Ar and $\mathrm{He}-\mathrm{Kr}$ calculated from mixing rules.

Figure 5. Dilute gas viscosity for $\mathrm{He}-\mathrm{Ar}$ and He-Kr calculated from mixing rules.

Figure 6. Relative regenerator thermal loss for He-Ar mixtures.

Figure 7. Relative regenerator thermal loss for He-Kr mixtures.

Figure 8. Relative pressure drop through regenerator for He-Ar mixtures.

Figure 9. Relative pressure drop through regenerator for He- $\mathrm{Kr}$ mixtures.

Figure 10. Sum of thermal and pressure losses in regenerator as a function of flow area.

Figure 11. Relative regenerator void volume as a function of heavy component fraction. 
List of Tables

Page

Table 1. Relative Enhancement of $S t\left(S t /(S t)_{\mathrm{PI}}=0.7\right)$ for $S t \sim 1 / \operatorname{Pr}^{\mathrm{n}}$ 

Effect of Noble Gas Mixtures on the Performance of

Regenerative-Type Cryocoolers--Analytical Estimate

David E. Daney

National Institute of Standards and Technology

Boulder, Colorado 80303

\begin{abstract}
We compare the performance of regenerators that use noble gas mixtures to the performance of those that use pure helium gas. Both helium-argon and helium-krypton mixtures are investigated. For some heat transfer surfaces, a modest gain in heat transfer can be achieved with these mixtures. The concomitant increase in pressure drop, however, more than offsets the heat transfer gain so the net regenerator loss increases for all cases we evaluated.

The dependence of heat transfer on Prandtl number has not been measured for the range associated with noble gas mixtures, $0.2<\operatorname{Pr}<0.5$, and we estimate that the uncertainty from this source can exceed 20 percent. We give our own estimates for the transport properties (Prandtl number, viscosity, and thermal conductivity) of helium-argon and helium-krypton mixtures because of the absence of experimental data at low temperature.
\end{abstract}

Key words: cryocoolers; gas mixtures; heat exchangers; heat transfer; noble gas mixtures; Prandt1 number; regenerators; thermal regenerators

\title{
1. Introduction
}

This report discusses the use of mixtures of noble gases with low Prandt 1 number to enhance the performance of regenerative-type cryocoolers such as Stirling cycle coolers. The potential for enhancement occurs because, all other factors being equal, the Prandt1 number determines how good the heat transfer is, and, hence, how low the thermal losses are in the regeneration of the cryocooler. Unfortunately, the changes in density, heat capacity, viscosity, and thermal conductivity that give rise to low Prandt 1 numbers in mixtures of noble gases generally degrade rather than enhance the performance.

The Prandtl number $\left(\operatorname{Pr} \equiv v / \alpha=\mu C_{p} / k\right)$ is the ratio of the momentum diffusivity (kinematic viscosity) to the thermal diffusivity. It is a measure 
of the relative speed at which momentum and energy are propagated through a convective system. For the simple case of laminar flow over a flat plate, the heat transfer coefficient is related to the Prandtl number by

$$
h \sim \frac{G \cdot C_{p}}{\operatorname{Re}^{1 / 2} \operatorname{Pr}^{2 / 3}}
$$

for $\operatorname{Pr}>1$ [1]. If other factors remain constant, then the lower the Prandtl number, the greater the heat transfer coefficient. For mixtures the molar heat capacity is constant, so the specific heat capacity changes with density in such a way that $G \cdot C_{p}$ is constant for constant velocity flow. The Reynolds number $\left(4 \rho V r_{h} / \mu\right)$, however, does not remain constant for constant velocity flow, but varies with density and viscosity in such a way as to generally give a net decrease in heat transfer for a constant velocity (constant machine speed), constant molar density system. For other types of flow and $0.1<\operatorname{Pr}<1--$ the range of interest here--the dependence of $h$ on $\operatorname{Pr}$ may differ somewhat.

In evaluating the effect gas mixtures have on the performance of regenerative cryocoolers, we avoid the general issue of optimization, because the number of variables is so great that we know of no truly general procedure. Thus it would not be clear whether the difference in performance between a machine "optimized" for mixtures and one "optimized" for helium would be due to the thermophysical properties of the two gases, or just the result of the optimization. We do consider one possible optimization where void volume in the regenerator is minimized for fixed values of regenerator ineffectiveness, pressure drop, and conduction loss. For that case, we calculate the effect of mixed gases on the regenerator void volume. A larger void volume requires the use of a larger compressor to maintain the same pressure ratio. Most of the effort in this paper compares thermal and pressure losses in the regenerator of a machine operating at the same speed and producing the same gross refrigeration with the same regenerator geometry. Both criteria require that the comparison be at constant pressure, because the refrigeration per mole of an ideal, monatomic gas is constant for the same pressure ratio and temperature. 


\section{Mixture Properties}

There are few data available on the transport properties of mixtures of noble gases below ambient temperature, so we had to estimate them. We took two different approaches. The first was to use kinetic theory of dilute gas mixture and the second virial equation of state [2]. Because of the limited time available, we did not "tune" parameters such as the potential well depth to give the best agreement with experimental properties. The second approach was to calculate the transport properties of the mixture from the pure component values by using mixing rules [3, 4, 5]. This empirical approach gives better agreement with the limited experimental results near ambient temperature. Consequently, we adopted the mixing rule method to generate the transport properties used in our heat transfer calculations.

Two different forms of mixing rules were used. The first,

$$
y=\frac{x_{1} y_{1}}{x_{1}+A\left(1-x_{1}\right)}+\frac{\left(1-x_{1}\right) y_{2}}{\left(1-x_{1}\right)+B x_{1}}
$$

where $x_{1} \quad=$ mole fraction of component 1

$\mathrm{y}_{1}, \mathrm{y}_{2}=$ transport property of pure components

$\mathrm{A}, \mathrm{B}=$ constants dependent on molecular species,

was used to estimate viscosity and thermal conductivity of helium-krypton mixtures as well as the viscosity of helium-argon mixtures. For the thermal conductivity of helium-argon mixtures, we used the expression

$$
y=\frac{x_{1} y_{1} A+\left(1-x_{1}\right) y_{2} B}{x_{1} A+\left(1-x_{1}\right) B}
$$

which is recommended by Stephan and Heckenberger [5] for the thermal conductivity of noble gas mixtures. We had already calculated the thermal conductivity of helium-krypton using equation (2) before coming across the Stephan-Heckenberger book, but the small difference in the results did not justify the extra work required to redo all the calculations.

In calculating the specific heat capacity, we assume that the molar heat capacity is constant. The heat capacity per unit mass is then

$$
C_{p}=\frac{20.79}{M_{1} \cdot x_{1}+M_{2}\left(1-x_{1}\right)}
$$

where $\mathrm{MW}_{1}$ and $\mathrm{MW}_{2}$ are the molecular weights of the pure components. 
In figure 1 we compare our dilute kinetic theory calculations for gas mixtures with equation (3) for a binary mixture of helium-krypton. The viscosities for the two methods agree well, but the thermal conductivities differ considerably. The difference in the Prandtl numbers results primarily from the difference in the thermal conductivities calculated by the two methods. Figure 2 compares the thermal conductivity calculated by the two methods with smoothed experimental values for the helium-argon system. This comparison is the basis for choosing mixing rule expressions 2 and 3 to generate the properties for our heat transfer calculations.

Figures 3, 4, and 5 show the Prandtl number, thermal conductivity, and viscosity used in the heat transfer calculations. The depression of Prandtl number in these gas mixtures occurs because the specific heat initially decreases faster than the thermal conductivity does. In contrast, liquid metals enjoy a low Prandt number in large part due to a high thermal conductivity.

For a gas mixture to be a useful refrigerant in a regenerative type cryocooler it is important that the mixture not condense in the cold part of the machine. Thus the dew point of the heavier component should be below the minimum operating temperature of the cooler. For mixtures of ideal gases, the dew point is equal to the saturation temperature of the pure heavier component. For mixtures of non-ideal gases, the dew point may be depressed below the saturation temperature of the pure components. The enhancement factor

$$
\phi=\frac{\mathrm{Py}_{1}}{\mathrm{P}_{01}}
$$

where $\mathrm{P}$ = total pressure

$\mathrm{y}_{1}=$ heavier component mole fraction

$\mathrm{P}_{\mathrm{O} 1}=$ vapor pressure of saturation heavier component

is a measure of how much the partial pressure of the heavier component may exceed the vapor pressure of the pure component. For example, if $\phi=1.2$ the partial pressure of the heavier component may be up to 20 percent greater than the saturated vapor pressure of the pure component before condensation occurs.

For He-Ar, the measured enhancement factor is 1.14 at 20 bar and $92 \mathrm{~K}$ [6]. For He-Kr the measured value is 1.09 at 20 bar and $110 \mathrm{~K}$ [7]. The enhancement factor is only a weak function of temperature, so the value at the dew point will differ only slightly. 


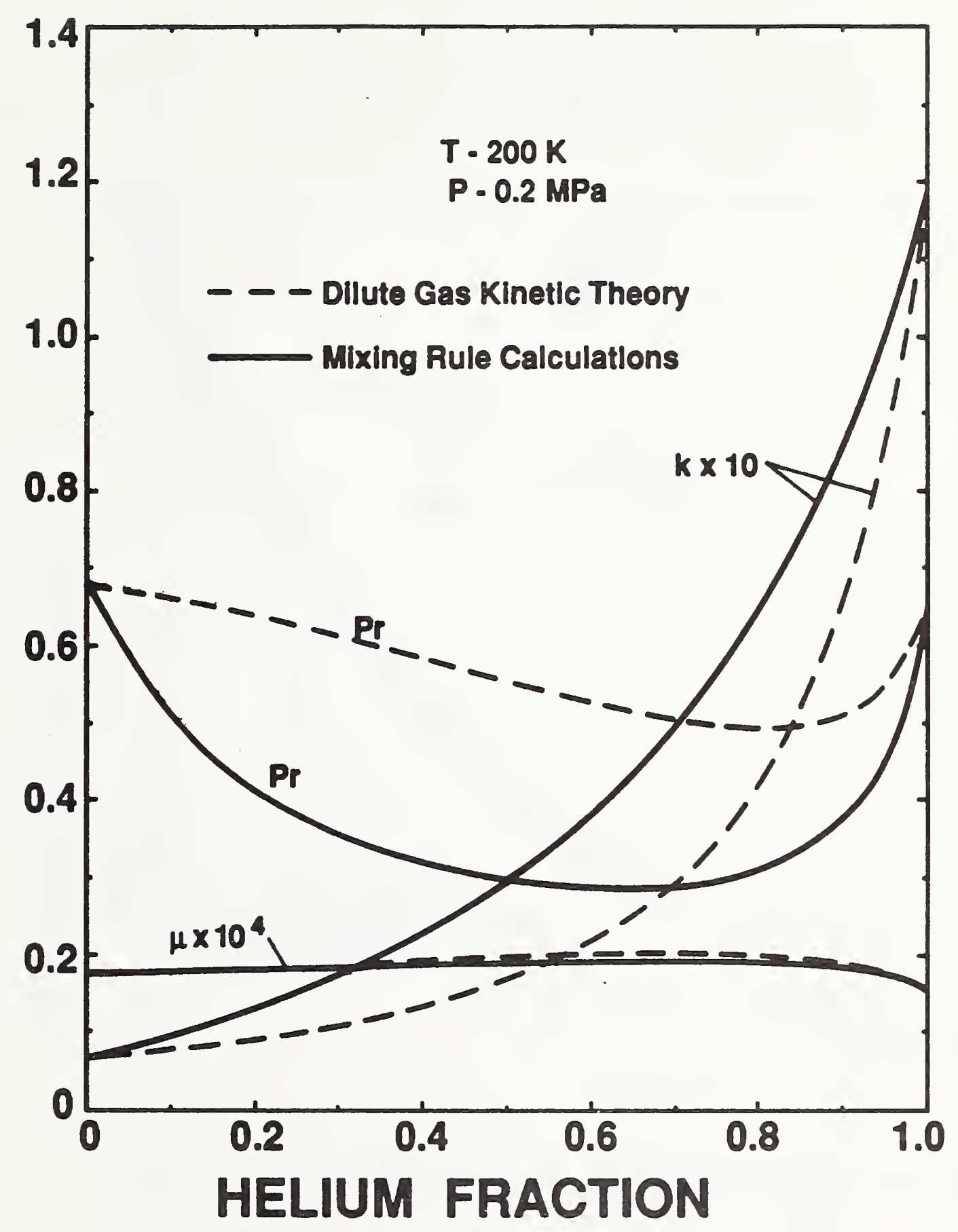

Figure 1. Transport properties of helium-krypton mixtures. 


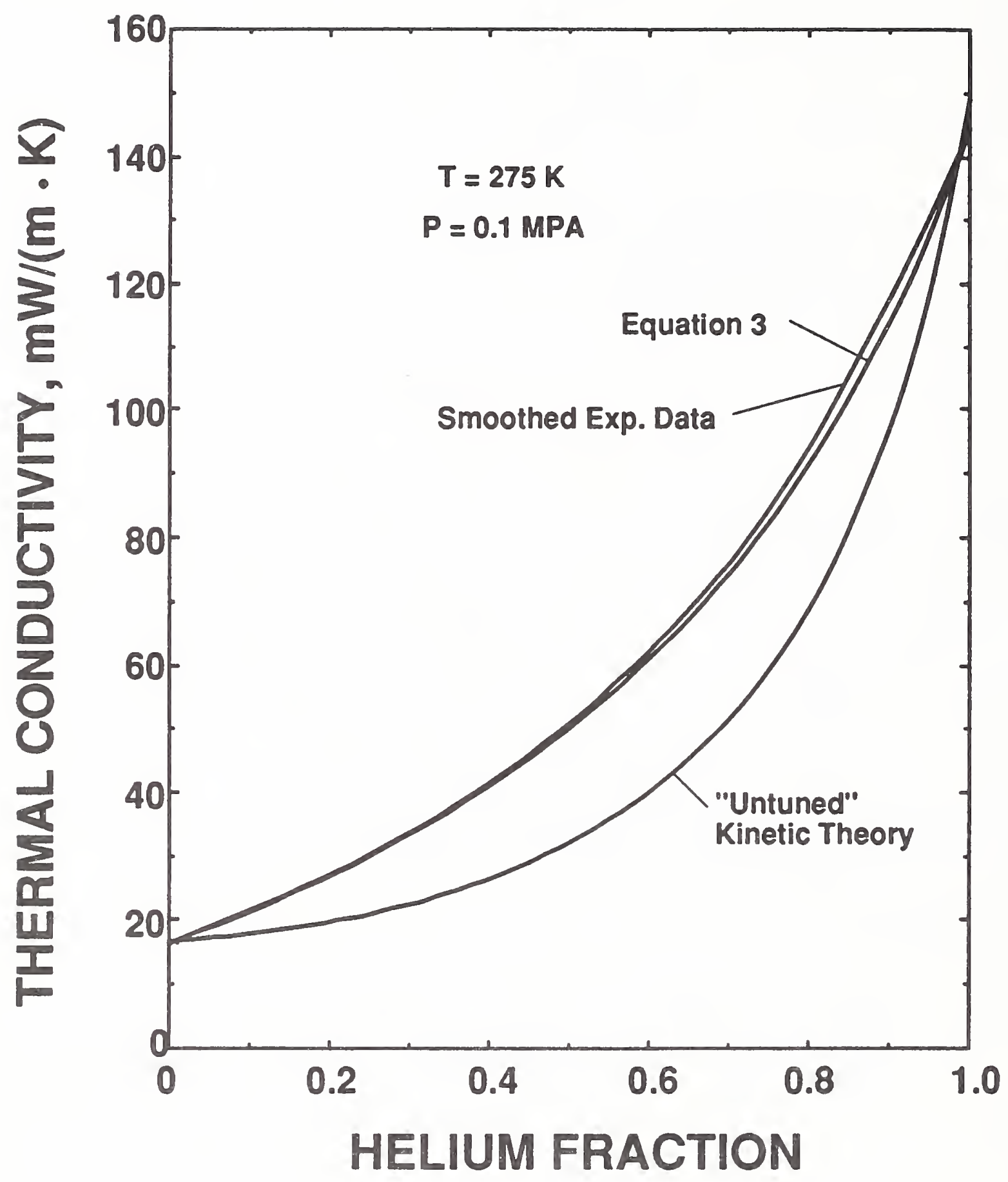

Figure 2. Thermal conductivity of helium-argon mixtures. 


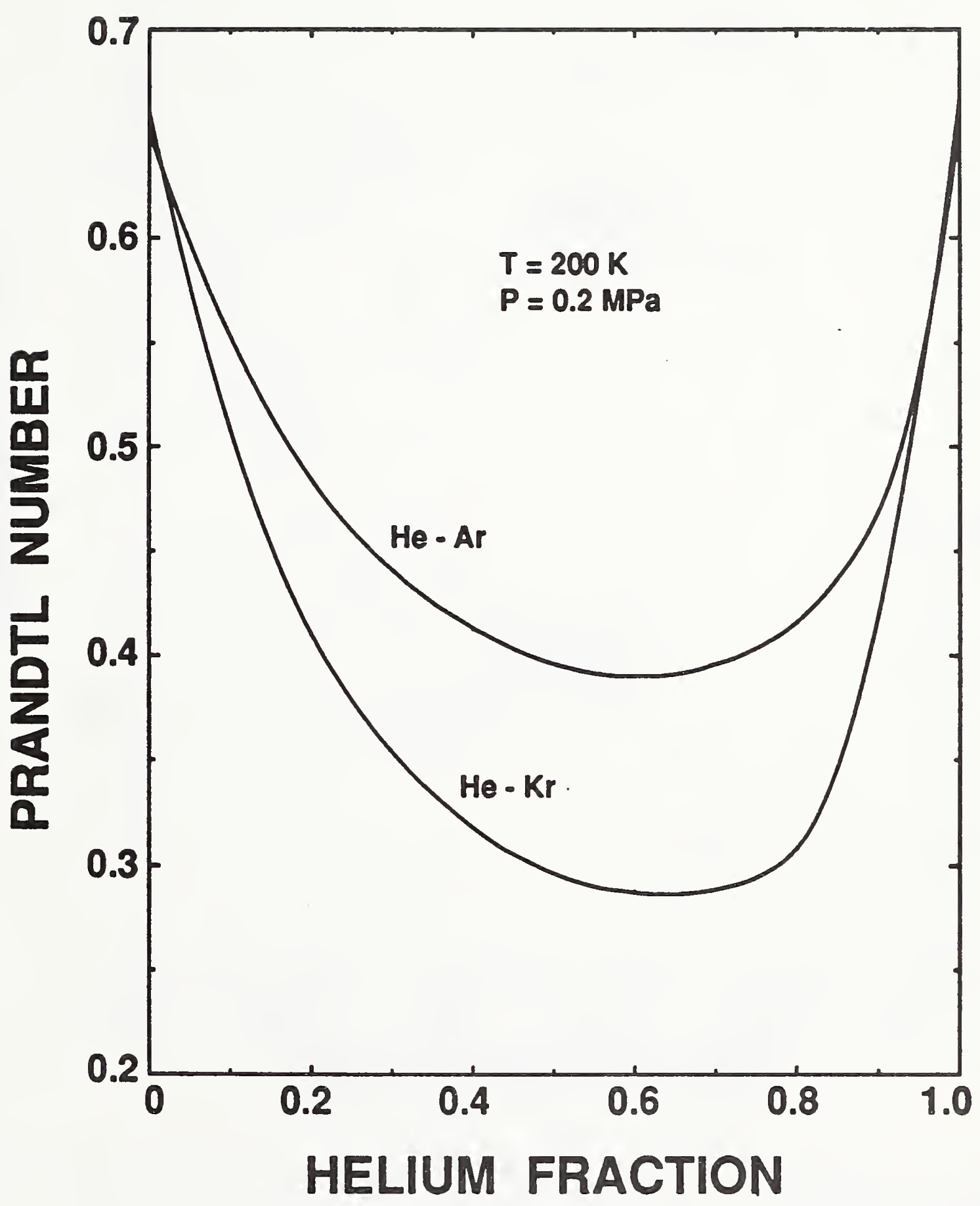

Figure 3. Dilute gas Prandtl number for $\mathrm{He}-\mathrm{Ar}$ and $\mathrm{He}-\mathrm{Kr}$ calculated from mixing rules. 


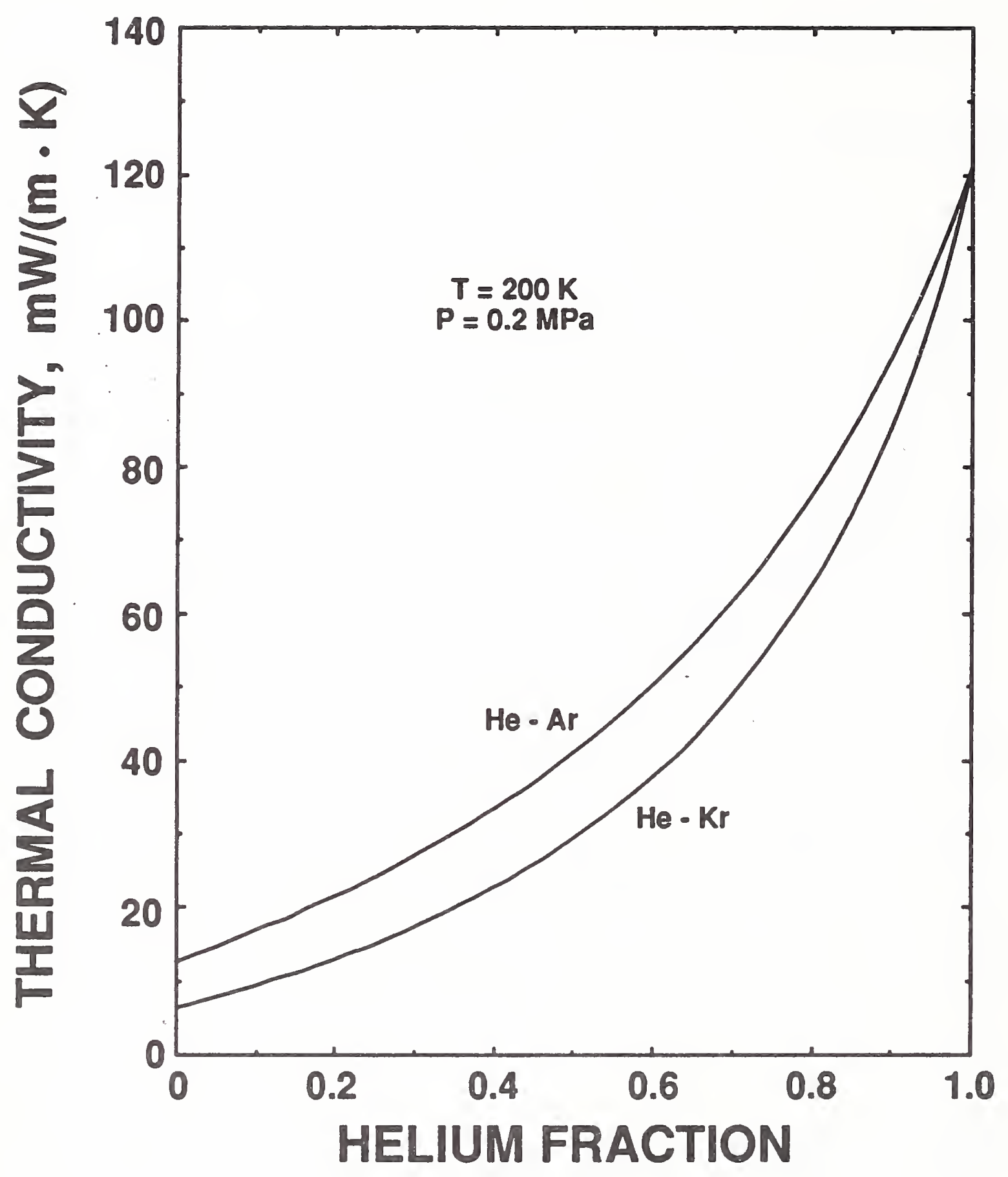

Figure 4. Dilute gas thernal conductivity for He-Ar and He-Kr calculated from mixing rules. 


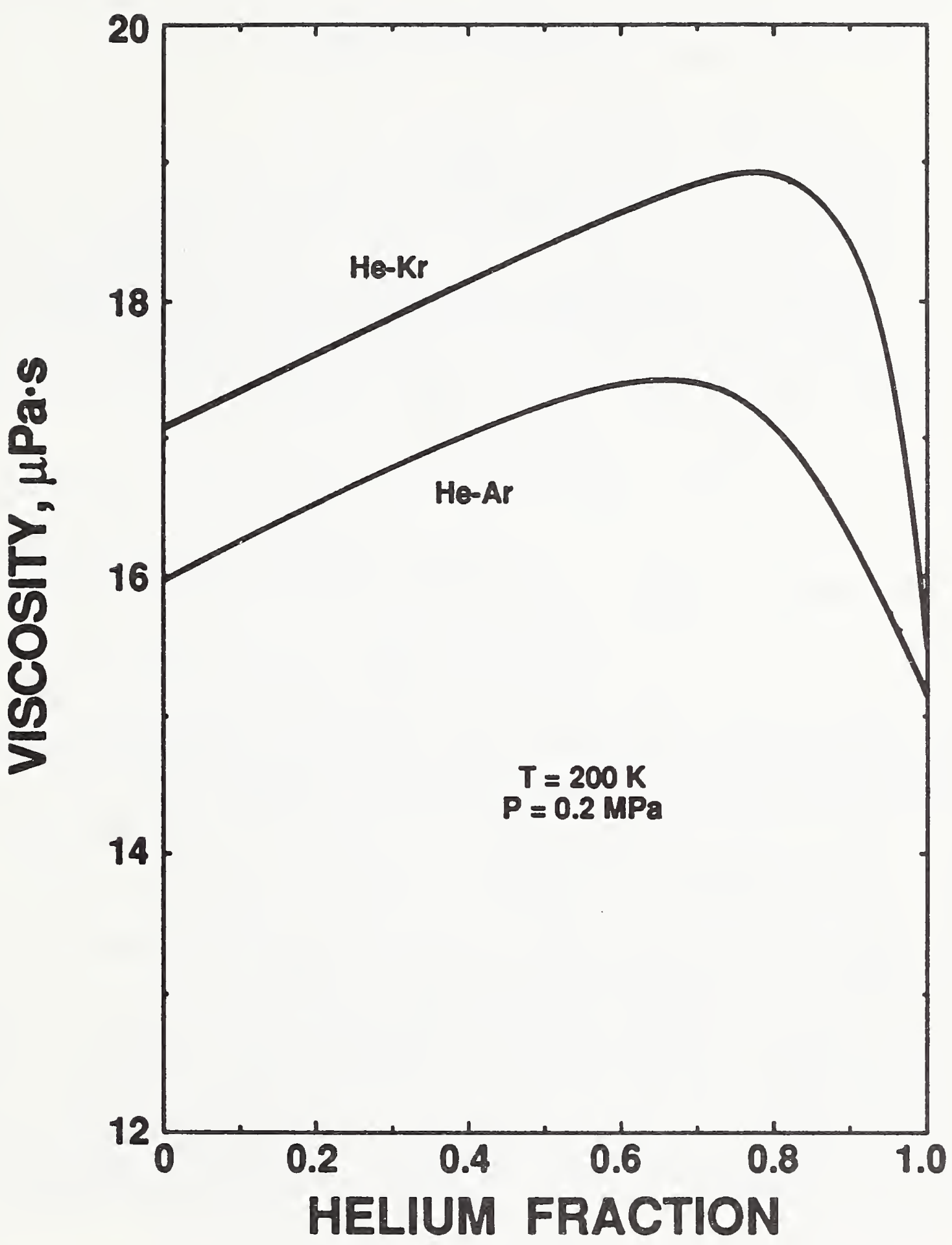

Figure 5. Dilute gas viscosity for $\mathrm{He}-\mathrm{Ar}$ and $\mathrm{He}-\mathrm{Kr}$ calculated from mixing rules. 
Thus we expect no major depression of the dew point of these mixtures at pressures up to 20 bar or so. An exact value for the lower useful temperature of these gas mixtures depends on pressure and mole fraction. A rough approximation, however, is given by the normal boiling point of the heavier component, which is $87 \mathrm{~K}$ for argon and $120 \mathrm{~K}$ for krypton.

3. Dependence of Heat Transfer on Prandtl Number

Results for heat transfer from compact heat exchanger surfaces are often presented by giving the Colburn " $j$ " factor $\left(j \equiv S t \operatorname{Pr}^{2 / 3}\right.$ ) as a function of the Reynolds number. For example, Compact Heat Exchangers by Kays and London [8], the definitive work on the subject, uses this method of presentation. As Kays and London are careful to point out, however, their measurements were all made with air $(\operatorname{Pr}=0.7)$, so the Prandtl number was not a test parameter.

The dependence of the Prandtl number on the two-thirds power comes from analytical solutions for laminar flow [1,9] which assume $\operatorname{Pr} \geq 1$. For this case the thickness of the thermal boundary layer is less than or equal to that of the momentum boundary layer, and the energy equation can be integrated in a single step from the wall to $\delta_{T}$. An integral method approximation to the heated flat plate problem gives the ratio of the thermal to momentum boundary thickness as $\zeta \equiv \delta_{\mathrm{T}} / \delta=1 / 1.026 \mathrm{Pr}^{1 / 3}$, and the local $\mathrm{j}$ factor as

$$
S t_{x} \operatorname{Pr}^{2 / 3}=\frac{0.332}{\operatorname{Re}_{x}^{1 / 2}}
$$

For $\operatorname{Pr}$ down to 0.6 the error in using $\operatorname{Pr}^{2 / 3}$ is quite small.

For $\operatorname{Pr}<1$, the thickness of the thermal boundary layer is greater than that of the momentum boundary layer and it becomes necessary to integrate the energy equation in two steps: wall to $\delta$ and $\delta$ to $\delta_{\mathrm{T}}-$-the second step being with uniform velocity. Using the integral technique, Eckert [10] obtained

$$
\mathrm{Nu}_{x}=\frac{\sqrt{\operatorname{RePr}}}{1.55 \sqrt{\mathrm{Pr}}+3.09 \sqrt{0.372-0.15 \mathrm{Pr}}}
$$

for a heated flat plate. For $\operatorname{Pr} \ll 1$ such as is the case for liquid metals,

$$
S t \sim \frac{1}{\operatorname{Pr}^{1 / 2} \operatorname{Re}^{1 / 2}}
$$


is a good approximation to expression 7 .

For $0.5>\operatorname{Pr}>0.1$--the region of interest for noble gas mixtures--the denominator in equation (7) varies such that

$$
N u_{x} \sim \operatorname{Pr}^{0} \cdot{ }^{39} \operatorname{Re}^{1 / 2}
$$

or,

$$
S t \sim \frac{1}{\operatorname{Pr}^{0.61} \mathrm{Re}^{1 / 2}}
$$

gives a good approximation.

For turbulent and separated flow, Zukauskas [11] shows that the exponent of the Prandtl number should be about 0.4 in the Nusselt number relation

$$
\mathrm{Nu}_{\mathrm{x}} \sim \operatorname{Pr}^{0.4}
$$

or -0.6 for the Stanton number relation

$$
S t \sim \frac{1}{\operatorname{Pr}^{0.6}} .
$$

Zukauskas's experiments were for fluids with $\operatorname{Pr}$ between 0.7 and 109 , and the exponent varied from 0.34 for a flat plate to 0.37 for a cylinder in cross flow. The moderately low range of Prandtl number was not investigated. Pickett, et al. [12] measured the turbulent heat transfer of helium-argon mixtures in tubes and found the expression recommended by Kays [13]

$$
\mathrm{Nu}=0.022 \operatorname{Re}^{0.8} \operatorname{Pr}^{0.6}
$$

correlated their data well for Prandtl number down to 0.42 . The DittusBoelter expression [14]

$$
\mathrm{Nu}=0.023 \operatorname{Re}^{0.8} \operatorname{Pr}^{0.4}
$$

overestimated the Nusslet number by 8 to 20 percent.

What we are left with is some uncertainty in the dependence of the heat transfer on the Prandt 1 number. An estimate of this uncertainty can be made by assuming that 


$$
\text { St } \sim \frac{1}{\mathrm{Pr}^{\mathrm{n}}}
$$

and evaluating the enhancement in $S t$ for various values of the exponent $n$ and $\operatorname{Pr}$, using $\mathrm{Pr}=0.7$ as the base--the value which was used in most heat transfer measurement for compact surfaces. Table 1 gives the results of such a comparison.

Table 1. Relative Enhancement of $S t\left(S t /(S t)_{\operatorname{Pr}}=0.7\right)$ for $S t \sim 1 / \operatorname{Pr}^{n}$

\begin{tabular}{lrcl} 
& \multicolumn{3}{c}{$\mathrm{n}$} \\
\cline { 2 - 3 } $\operatorname{Pr}$ & $2 / 3$ & 0.6 & 0.5 \\
0.6 & 1.11 & 1.10 & 1.08 \\
0.5 & 1.25 & 1.22 & 1.18 \\
0.4 & 1.45 & 1.40 & 1.32 \\
0.3 & 1.76 & 1.66 & 1.53 \\
0.2 & 2.31 & 2.12 & 1.87 \\
0.1 & 3.66 & 3.21 & 2.65
\end{tabular}

For modestly low $\operatorname{Pr}($ say $\operatorname{Pr}=0.4$ ) we expect an error of 10 percent in $S t$ if the correct value of $\mathrm{n}$ is 0.5 rather than 2/3. For a mixture with $\operatorname{Pr}$ as low as 0.2 , the possible error jumps to 24 percent.

4. Heat Transfer

The influence of heat transfer on the performance of a regenerative refrigerator can be expressed in terms of the regenerator's thermal loss $\dot{Q}_{\text {reg }}$. Radebaugh, Louie, and Arp [15,16] show that the dimensionless thermal loss is given by

$$
\frac{\dot{\mathrm{Q}}_{\mathrm{r} \Theta \mathrm{g}}}{\dot{\mathrm{Q}}_{\mathrm{r}}}=(1-\epsilon)\left(\frac{\mathrm{H}_{\mathrm{U}}-\mathrm{H}_{\mathrm{L}}}{\mathrm{q}_{\mathrm{r}}}\right)
$$

where $\epsilon=$ regenerator effectiveness.

The regenerator ineffectiveness is a complex function of several variables,

$$
1-\epsilon=I\left(N T U, \operatorname{Cr} / C_{f}, C_{m i n} / C_{m a x}, C_{v o i d} / C_{f}\right)
$$


For the special case of $C_{v o i d} / C_{f}=0, C_{\min } / C_{\max }=1$, and $C_{x} / C_{f}>>1$ the relationship is given exactly by [8]

$$
1-\epsilon=\frac{2}{2+N T U} \text {, }
$$

which is identical with the expression for a counterflow heat exchanger. For regenerators with large NTU which are typical of cryocooler regenerators, $C_{r} / C_{f}$ is generally large for a cryocooler operating at $80 \mathrm{~K}$ and above, because the large surface area required also results in high matrix heat capacity. For our analysis it is more convenient to approximate equation (14) by

$$
1-\epsilon=\frac{1.89}{N T U^{0} .992} \text {, }
$$

which agrees with (14) within 1 percent for NTU greater than 50.

The NTU is related to the Stanton number $\left(S t \equiv h / G \cdot C_{p}\right.$ ) by

$$
\mathrm{NTU}=\operatorname{St}\left(\mathrm{A} / \mathrm{A}_{\mathrm{g}}\right)
$$

Substituting (15) and (16) into (12) gives

$$
\frac{\dot{Q}_{r \theta g}}{\dot{Q}_{r}}=\frac{1.89}{\left(A / A_{g}\right)}\left(\frac{H_{U}-H_{L}}{q_{r}}\right) \frac{1}{S t^{0.992}}
$$

as the relationship between the stanton number and the thermal loss in either a regenerator or counterflow heat exchanger with balanced flow.

The relationship between the Stanton number and the Reynolds number depends on the geometry of the flow passage, so no general conclusion is possible in relating the refrigerant properties to thermal losses. Instead, we consider four particular geometries: screens, randomly packed spheres, gap passages with laminar flow, and circular tubes with turbulent flow. 


\subsection{Screens}

We use the expression from Kays and London [8]

$$
S t \cdot \operatorname{Pr}^{2 / 3}=K_{S c}(p) \operatorname{Re}^{-0.43}
$$

for the heat transfer in screen regenerators. Substituting (18) into (17) gives

$$
\frac{\dot{Q}_{r \theta g}}{\dot{Q}_{r}}=\frac{1.89}{\left[\mathrm{~A} / \mathrm{A}_{\mathrm{g}} \cdot \mathrm{K}_{\mathrm{Sc}}(\mathrm{p})\right]^{0.992}}\left(\frac{\mathrm{H}_{U}-\mathrm{H}_{\mathrm{L}}}{\mathrm{q}_{\mathrm{r}}}\right) \operatorname{Pr}^{0.66 \mathrm{R}_{e} 0.43 .}
$$

For a fixed geometry and pressure, equation (19) gives

$$
\frac{\dot{Q}_{r \otimes 82}}{\dot{Q}_{r \otimes 81}}=\left(\frac{\mathrm{Pr}_{2}}{\mathrm{Pr}_{1}}\right)^{0.66}\left(\frac{\mathrm{MW}_{2}}{\mathrm{MW}}\right)^{0.43}\left(\frac{\mu_{1}}{\mu_{2}}\right)^{0.43} .
$$

\subsection{Spheres}

We again turn to Kays and London [8] and use

$$
S t \cdot \operatorname{Pr}^{2 / 3}=K_{S p}(p) \operatorname{Re}^{-0.3}
$$

to obtain

$$
\frac{\dot{Q}_{r \in 82}}{\dot{Q}_{r \in 81}}=\left(\frac{\operatorname{Pr}_{2}}{\operatorname{Pr}_{1}}\right)^{0.66}\left(\frac{M W_{2}}{M W_{1}}\right)^{0.3}\left(\frac{\mu_{1}}{\mu_{2}}\right)^{0.3} .
$$

\subsection{Gaps}

For laminar flow in gaps the Stanton number is given by [8]

$$
S t \cdot \operatorname{Pr}^{2 / 3}=K_{G} \operatorname{Re}^{-1} \text {, }
$$

which yields

$$
\frac{\dot{Q}_{\mathrm{re82}}}{\dot{\mathrm{Q}}_{\mathrm{re81}}}=\left(\frac{\mathrm{Pr}_{2}}{\mathrm{Pr}_{1}}\right)^{0.66}\left(\frac{\mathrm{MW}_{2}}{\mathrm{MW}_{1}}\right)^{0.99}\left(\frac{\mu_{1}}{\mu_{2}}\right)^{0.99} .
$$




\subsection{Tubes}

For turbulent flow through tubes, we use the Colburn expression $[1,14]$

$$
\mathrm{St} \cdot \mathrm{Pr}^{2 / 3}=0.023 \mathrm{Re}^{-0.2}
$$

which gives

$$
\frac{\dot{Q}_{r e 82}}{\dot{Q}_{r \otimes 81}}=\left(\frac{\operatorname{Pr}_{2}}{P r_{1}}\right)^{0.66}\left(\frac{M W_{2}}{M W_{1}}\right)^{0.2}\left(\frac{\mu_{1}}{\mu_{2}}\right)^{0.2} .
$$

An alternative approach, which is equivalent and yields the same numerical results, is to formulate the problem in terms of the heat transfer coefficient. For tubes with turbulent flow, the Nusselt number equivalent of (25) is

$$
\mathrm{Nu}=0.023 \mathrm{Re}^{0.8} \mathrm{Pr}^{1 / 3}
$$

or

$$
\mathrm{h}=\frac{0.023}{\mathrm{D}_{\mathrm{h}}} \mathrm{k}\left(\frac{\rho \mathrm{VD}_{\mathrm{h}}}{\mu}\right)^{0.8}(\mathrm{Pr})^{1 / 3}
$$

and

$$
\frac{h_{2}}{h_{1}}=\left(\frac{k_{2}}{k_{1}}\right)\left(\frac{\rho_{2}}{\rho_{1}}\right)^{0.8}\left(\frac{\mu_{1}}{\mu_{2}}\right)^{0.8}\left(\frac{\mathrm{Pr}_{2}}{\mathrm{Pr}_{1}}\right)^{1 / 3}
$$

The relative thermal loss, using equations 12 and 14 , is related to the heat transfer coefficient by

$$
\frac{\dot{Q}_{\text {re82 }}}{\dot{Q}_{\text {reg1 }}}=\frac{1}{\left(h_{2} / h_{1}\right)^{0.992}} .
$$

Figures 6 and 7 show the relative thermal loss, $Q_{\text {reg } 2} / Q_{\text {reg 1 }}$, for He-Ar and He$\mathrm{Kr}$ mixtures. Only tubes and packed spheres show improved heat transfer (reduced thermal loss), and only He-Kr mixtures in tubes show enough improvement to be interesting. 


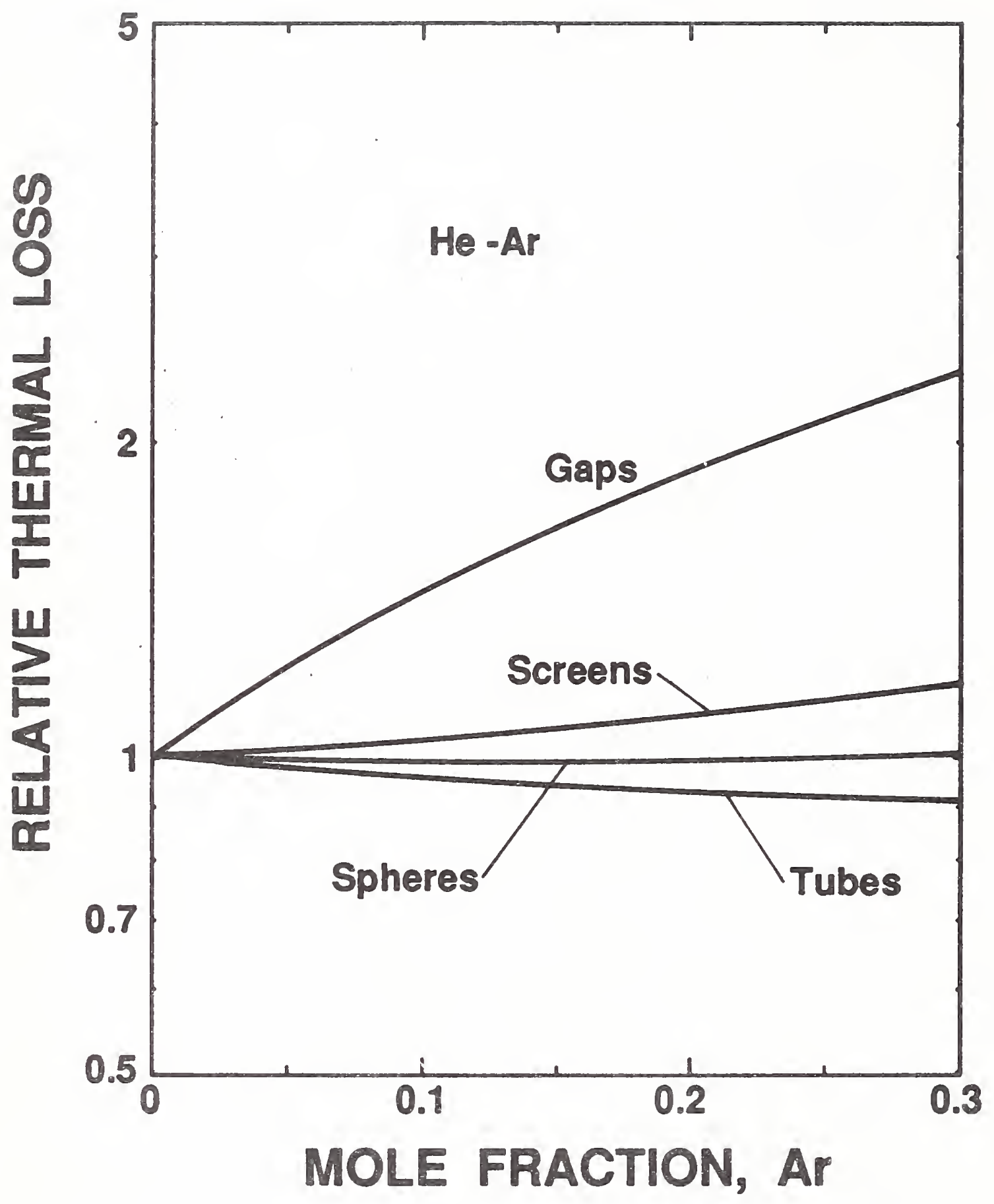

Figure 6. Relative regenerator thermal loss for He-Ar mixtures. 


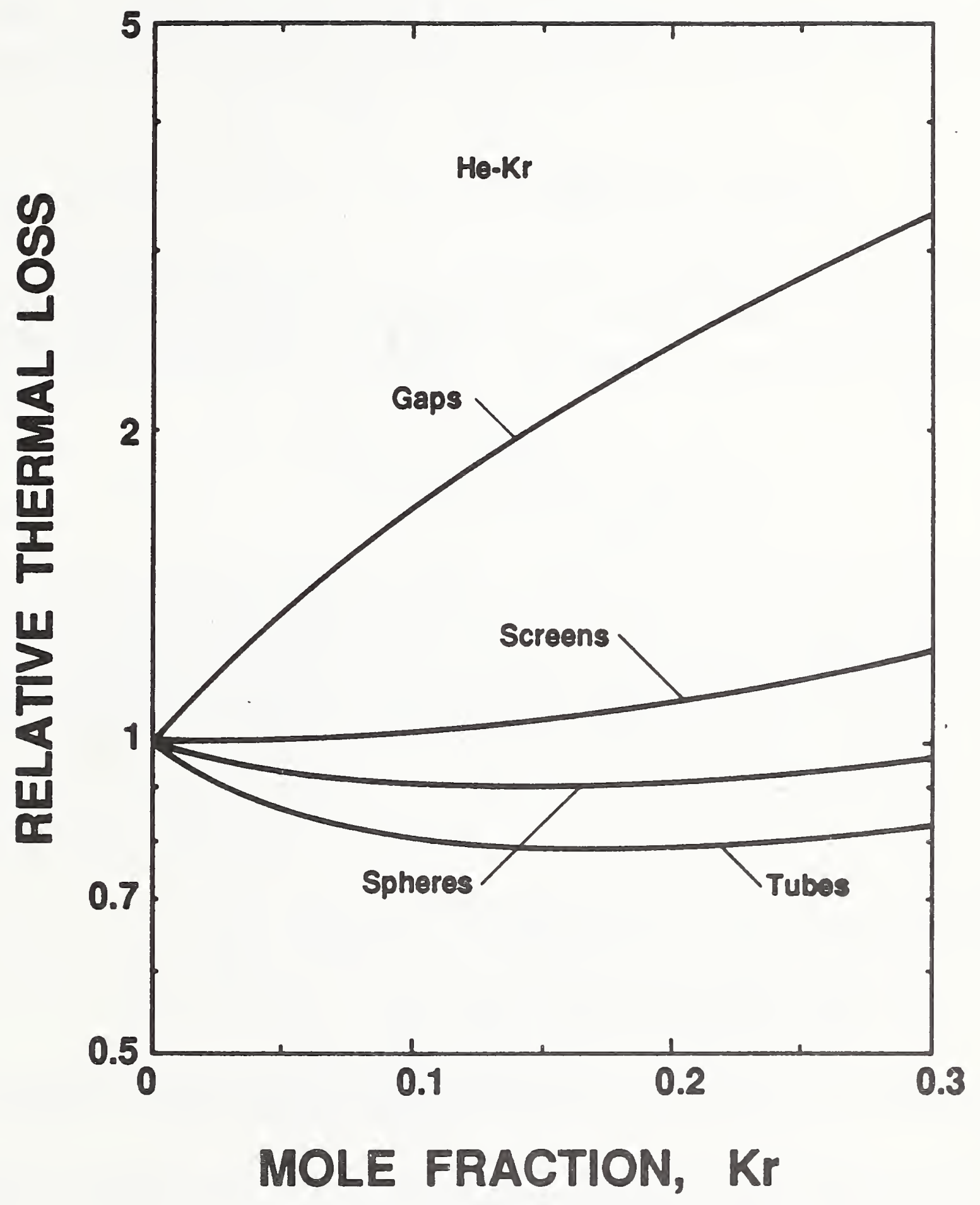

Figure 7. Relative regenerator thermal loss for He-Kr mixtures. 
5. Pressure Drop

The pressure drop in the case of the regenerator is given by

$$
\Delta \mathrm{P}=\mathrm{f} \frac{\mathrm{L}}{\mathrm{r}_{\mathrm{h}}} \rho \frac{\mathrm{V}^{2}}{2}
$$

To simplify the calculations, we adopt a modified Colburn analogy [1] and assume that the gas friction is related to the heat transfer by the expression [15]

$$
f=\frac{S t r^{2} / 3}{\alpha}
$$

where the parameter $\alpha$ is taken as a constant for a particular geometry. In fact, $\alpha$ is sometimes a weak function of the Reynolds number, but for our purposes assuming constant $\alpha$ is adequate. Combining equations (31) and (32) gives

$$
\frac{\Delta \mathrm{P}}{\mathrm{P}}=\left(\frac{\mathrm{L}}{2 \mathrm{r}_{\mathrm{h}} \alpha}\right)\left(\frac{\mathrm{V}^{2}}{\mathrm{P}}\right) \rho \mathrm{StPr} \mathrm{Pr}^{2 / 3}
$$

The first grouping of terms on the RHS is fixed by the geometry of the regenerator and the second grouping depends on the operating conditions -machine speed and fill pressure. As with the heat transfer, we consider four geometries: screens, randomly packed spheres, gap passages with laminar flow, and circular tubes with turbulent flow.

\subsection{Screens}

Substituting (18) into (33) we obtain

$$
\frac{\Delta \mathrm{P}}{\mathrm{P}}=\left(\frac{\mathrm{K}_{\mathrm{sc}}(\mathrm{p}) \mathrm{L}}{2 \mathrm{r}_{\mathrm{h}} \alpha}\right)\left(\frac{\mathrm{V}^{2}}{\mathrm{P}}\right)\left(\frac{\rho}{\mathrm{Re}^{0.43}}\right) .
$$

For the same geometry, operating speed, and pressure the relative pressure drop is then

$$
\frac{\Delta \mathrm{P}_{2}}{\Delta \mathrm{P}_{1}}=\left(\frac{\rho_{2}}{\rho_{1}}\right)^{0.57}\left(\frac{\mu_{2}}{\mu_{1}}\right)^{0.43}
$$




\subsection{Randomly Packed Spheres}

Substituting (21) into (33) gives

$$
\frac{\Delta \mathrm{P}}{\mathrm{P}}=\left(\frac{\mathrm{K}(\mathrm{P})_{\mathrm{sp}} \mathrm{L}}{2 r_{\mathrm{h}} \alpha}\right)\left(\frac{\mathrm{V}^{2}}{\mathrm{P}}\right)\left(\frac{\rho}{\mathrm{Re}^{0 \cdot 3}}\right),
$$

and

$$
\frac{\Delta \mathrm{P}_{2}}{\Delta \mathrm{P}_{1}}=\left(\frac{\rho_{2}}{\rho_{1}}\right)^{0.7}\left(\frac{\mu_{2}}{\mu_{1}}\right)^{0.3},
$$

for the same machine operating at the same speed and pressure.

\subsection{Gas with Laminar Flow}

Substituting (23) into (33) gives

$$
\frac{\Delta \mathrm{P}}{\mathrm{P}}=\left(\frac{\mathrm{K}_{\mathrm{G}} \mathrm{L}}{2 \mathrm{r}_{\mathrm{h}} \alpha}\right)\left(\begin{array}{l}
\mathrm{V}^{2} \\
\mathrm{P}
\end{array}\right)\left(\frac{\rho}{\operatorname{Re}}\right),
$$

and

$$
\frac{\Delta \mathrm{P}_{2}}{\Delta \mathrm{P}_{1}}=\left(\frac{\mu_{2}}{\mu_{1}}\right)
$$

which is the expected result for pure laminar flow.

\subsection{Tubes with Turbulent Flow}

Substituting (25) into (33) gives

$$
\frac{\Delta \mathrm{P}}{\mathrm{P}}=\left(\frac{\mathrm{K}_{\mathrm{T}} \mathrm{L}}{2 \mathrm{r}_{\mathrm{h}} \alpha}\right)\left(\frac{\mathrm{V}^{2}}{\mathrm{P}}\right)\left(\frac{\rho}{\mathrm{Re}^{0 \cdot 2}}\right),
$$

and

$$
\frac{\Delta \mathrm{P}_{2}}{\Delta \mathrm{P}_{1}}=\left(\frac{\rho_{2}}{\rho_{1}}\right)^{0.8}\left(\frac{\mu_{2}}{\mu_{1}}\right)^{0.2}
$$

Figures 8 and 9 give the ratio of the pressure drop of the mixture to that of helium for $\mathrm{He}-\mathrm{Ar}$ and He-Kr mixtures. In all cases, mixtures give increased pressure drop, and for screens, spheres, and tubes the effect of density makes these increases large. 


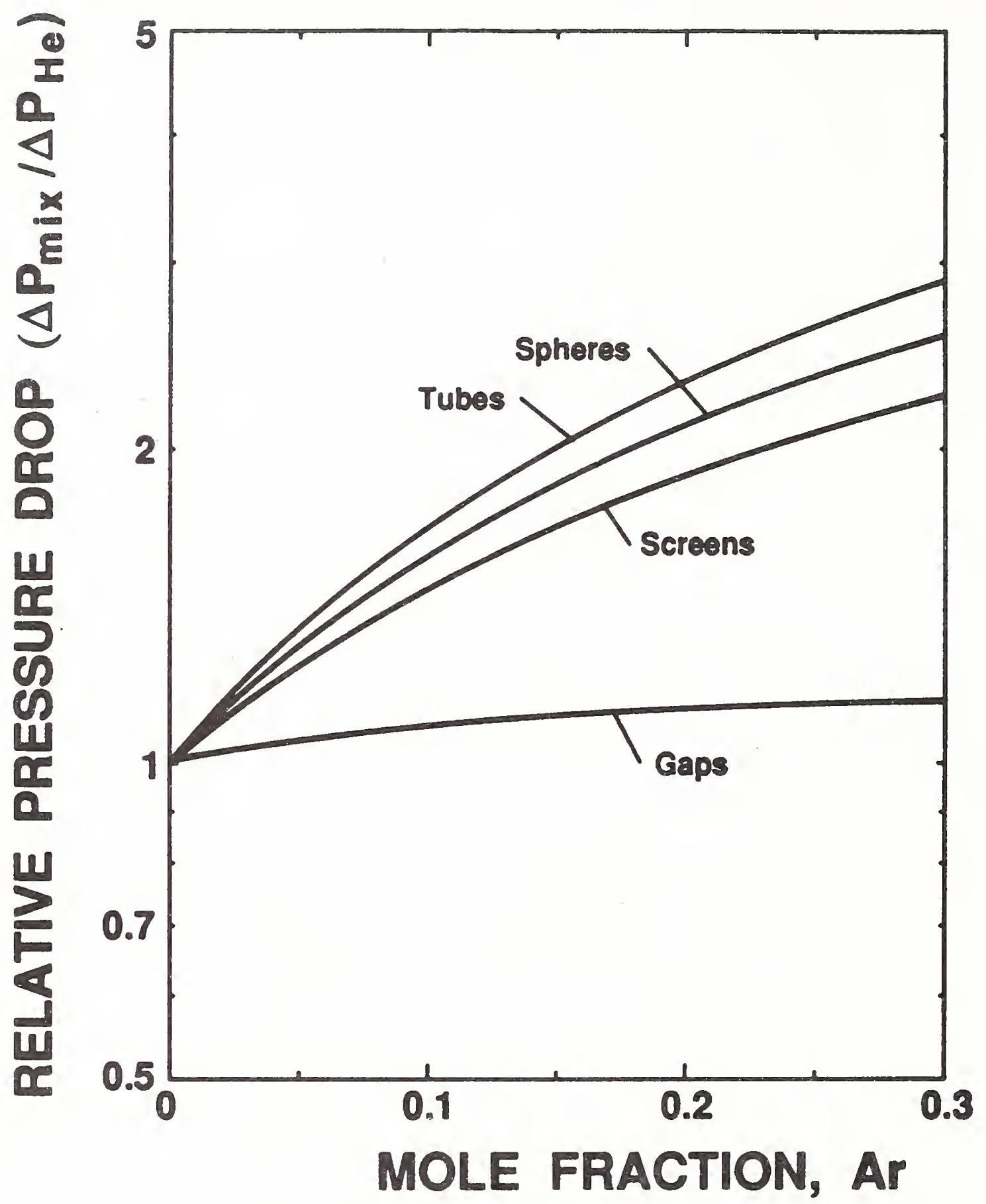

Figure 8. Relative pressure drop through regenerator for He-Ar mixtures. 


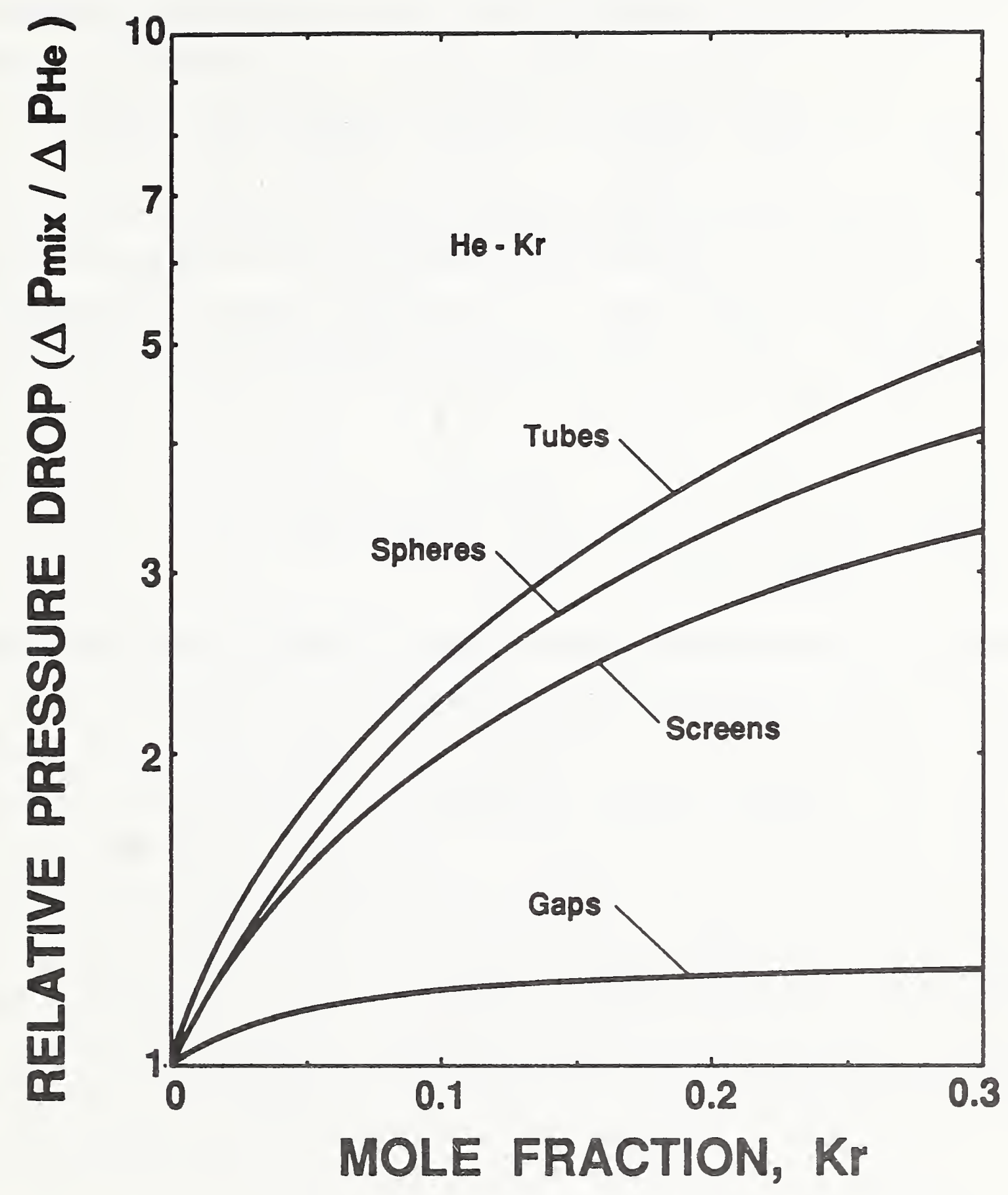

Figure 9. Relative pressure drop through regenerator for $\mathrm{He}-\mathrm{Kr}$ mixtures. 


\section{Discussion}

The use of noble gas mixtures in regenerative cryocoolers does not appear to give an overall enhancement in performance. For example, although a reduction of 10 percent in the thermal loss of a sphere regenerator can be achieved with a 0.1 mole fraction $\mathrm{Kr}$, He-Kr mixture, the resulting 227-percent increase in pressure drop would give a net loss of performance in a welldesigned regenerator.

The loss associated with the high pressure drop of the mixture can be mitigated by increasing the flow area of the regenerator--although at the expense of increasing the thermal loss. We analyze the effect of flow area on the thermal and pressure losses by combining equations 17 and 21 to get, for spheres,

$$
\frac{\dot{Q}_{r \theta g}}{\dot{Q}_{I}}=\frac{1.89}{\left[\mathrm{~A} / \mathrm{Ag} \cdot \mathrm{K}_{\mathrm{Sp}}(\mathrm{P})\right]^{0.992}}\left(\frac{\mathrm{H}_{\mathrm{U}}-\mathrm{H}_{\mathrm{L}}}{\mathrm{q}_{\mathrm{r}}}\right) \operatorname{Pr}^{0.66} \operatorname{Re}^{0.43} .
$$

If we hold constant the regenerator surface area, $A$, and the hydraulic radius, $r_{h}$, then the volume of the regenerator is constant

$$
\text { Volume } \sim \mathrm{LA}_{\mathrm{g}}=\text { constant: }
$$

or

$$
L \sim \frac{1}{A_{g}}
$$

and the velocity $V$ is related to the flow area by

$$
\mathrm{V} \sim \frac{1}{\mathrm{~A}_{\mathrm{g}}}
$$

Substituting (43) into (42) gives

$$
\frac{\dot{Q}_{r e g}}{\dot{Q}_{r}} \sim A_{g} 0.69
$$

In a similar fashion, we obtain the pressure loss as 


$$
\frac{\dot{Q}_{P}}{\dot{Q}_{r}} \sim \frac{\Delta P}{P} \sim A_{g}-2 \cdot 7
$$

The sum of the pressure and thermal losses as a function of flow area is then

$$
\frac{\dot{Q}_{r \in 8}}{\dot{Q}_{r}}+\frac{\dot{Q}_{P}}{\dot{Q}_{r}}=\left(\frac{\dot{Q}_{r \in g}}{\dot{Q}_{r}}\right)_{0}\left(\frac{A_{g}}{A_{g}}\right)^{0.69}+\left(\frac{\dot{Q}_{P}}{\dot{Q}_{r}}\right)_{0}\left(\frac{A_{g}}{A_{g 0}}\right)^{-2.7},
$$

where the subscript o refers to some given reference geometry.

In figure 10, we use equation 45 to compare the combined pressure and thermal losses for a regenerator having $\dot{Q}_{r e g} / \dot{Q}_{r}=\dot{Q}_{P} / \dot{Q}_{r}=0.1$ as a reference condition for two gases--pure helium and the helium-krypton mixture of 0.1 mole fraction krypton cited above. Although increasing the flow area $\mathrm{Ag}_{\mathrm{g}}$ does much to mitigate the increased pressure loss for the mixture, the losses for the mixture are never quite as low as the minimum for pure helium. The heat conduction loss is not included in figure 10, so the optimum regenerator does not occur at the minimum in the curves. Instead the optimum will be at a lower value of $A_{g} / A^{g}$ 。 because the conduction loss goes as $\left(A_{g} / A_{0}\right)^{2}$.

Regenerator void volume has a significant effect on the performance of regenerative cryocoolers, and in general, the smaller the void volume, the greater the efficiency. For ideal, loss-free stirling coolers, increased void volume reduces the cooling power, but not the efficiency, which is always 100 percent of Carnot efficiency. For non-ideal stirling coolers, however, increased void volume reduces the efficiency by compounding the effect of thermal and pressure losses.

We estimate the effect of mixtures on the void volume of the regenerator by using the expression

$$
\mathrm{V}_{\mathrm{rg}} / \mathrm{V}_{\mathrm{e}}=\rho_{\mathrm{e}}\left[\frac{2 \operatorname{NTU}\left(\mathrm{C}_{\mathrm{r}} / \mathrm{C}_{\mathrm{f}}\right) \mathrm{Pr}^{2 / 3} \omega \mathrm{C}_{\mathrm{p}} \int k \mathrm{dT}}{\alpha \rho \Delta \mathrm{q}_{\mathrm{r}}\left(\dot{\mathrm{Q}}_{\mathrm{c}} / \dot{\mathrm{Q}}_{\mathrm{r}}\right)\left(\rho_{\mathrm{m}} \mathrm{C}_{\mathrm{m}}\right)}\right]
$$

of Radebaugh and Louie [15] which relates the regenerator void volume to regenerator losses and thermal properties of the working fluid. If we note that $\rho q_{r}$ in the denominator can be expressed as $\left(\rho / \rho_{e}\right) \rho_{e} q_{r}$ and that $\rho_{e} q_{r}$, the 


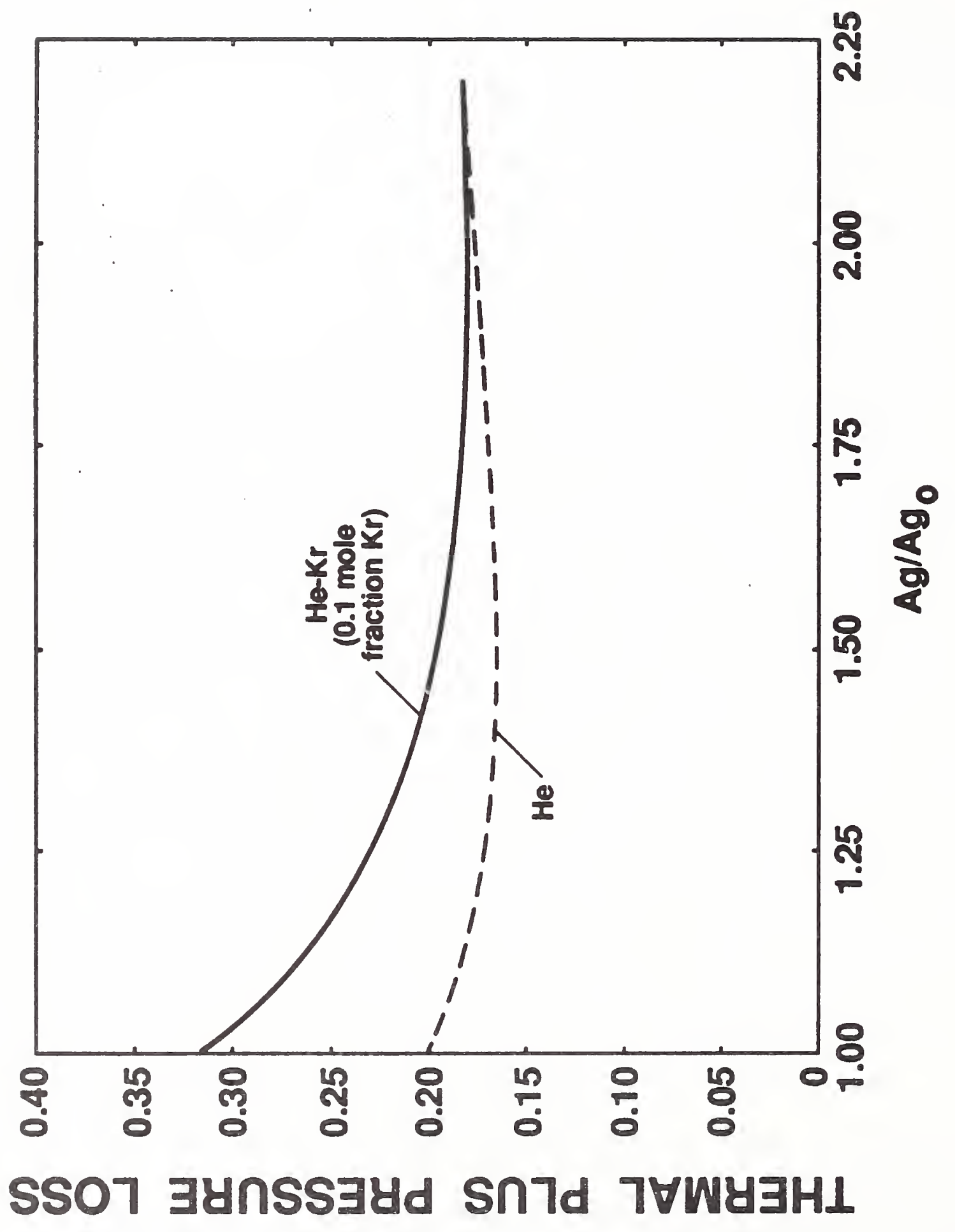

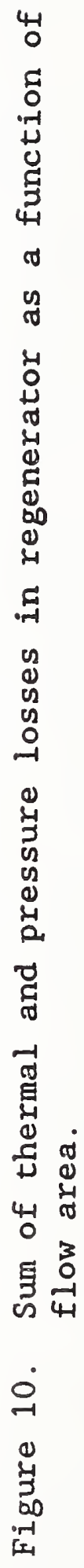


refrigeration per unit volume of the expansion space, is independent of the mixture mole fraction, then

$$
\mathrm{V}_{\mathrm{rg}} / \mathrm{V}_{\mathrm{e}} \sim \rho_{\mathrm{e}}\left[\mathrm{Pr}^{2 / 3} \mathrm{C}_{\mathrm{p}}\right]^{1 / 2}
$$

gives the relationship between the void volume and mixture properties when the regenerator ineffectiveness, pressure drop, and conduction loss are held constant. Noting that the molar heat capacity and density are constant, we use

$$
C_{p}=\frac{C}{M}
$$

and

$$
\rho=\mathrm{M} \rho_{M}
$$

to obtain

$$
\mathrm{V}_{\mathrm{rg}} / \mathrm{V}_{\mathrm{e}} \sim \operatorname{Pr}^{1 / 3} \mathrm{M}^{1 / 2}
$$

as the relationship between the regenerator void volume, mixture Prandtl number, and molecular weight.

Figure 11 shows that both He-Ar and He-Kr mixtures increase the regenerator void volume over that for pure helium.

The heat transfer strongly depends on the geometry of the heat transfer surface as illustrated by figures 6 and 7. In general, the weaker the dependence of the Stanton number on the Reynolds number, the greater the enhancement of heat transfer. If we express the relationship between St and Re in the general form

$$
S t \cdot \operatorname{Pr}^{2 / 3}=K \operatorname{Re}^{-n}
$$

then the thermal loss in the regenerator is

$$
\frac{\dot{Q}_{r \oplus g}}{\dot{Q}_{r}}=\frac{1.89}{[(\mathrm{~A} / \mathrm{Ag}) \mathrm{K}]^{0.99}}\left(\frac{\mathrm{H}_{U}-\mathrm{H}_{\mathrm{L}}}{\mathrm{q}_{\mathrm{r}}}\right) \operatorname{Pr}^{0.66} \mathrm{Re}^{0.99 \mathrm{n}}
$$




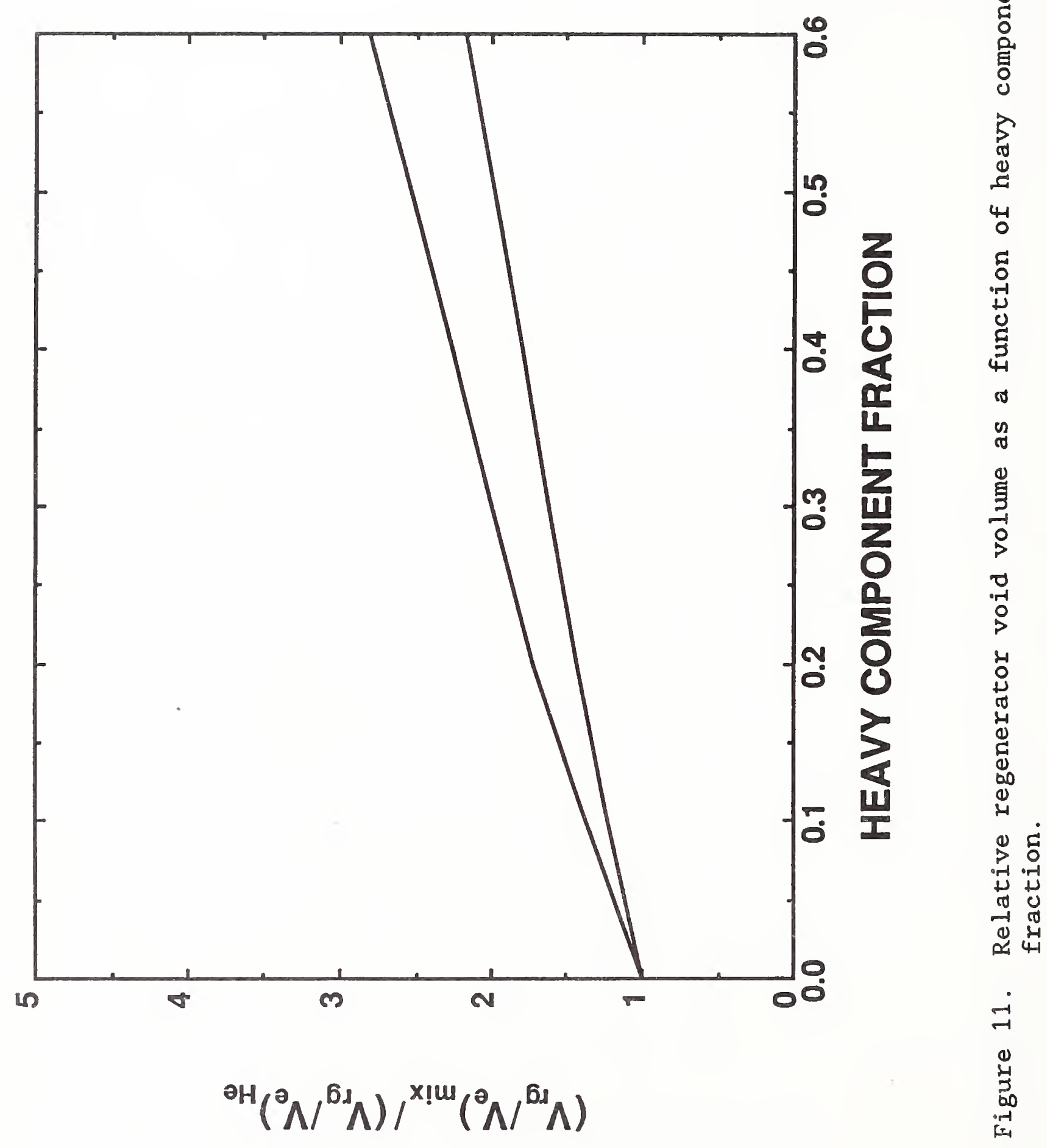


and

$$
\frac{\dot{Q}_{r \in g 2}}{\dot{Q}_{r \in g 1}}=\left(\frac{\operatorname{Pr}_{2}}{\operatorname{Pr}_{1}}\right)^{0.66}\left(\frac{M_{2}}{M W_{1}}\right)^{0.99 n}\left(\frac{\mu_{1}}{\mu_{2}}\right)^{0.99 n} .
$$

Because the molecular weight increases more rapidly than the Prandtl number decreases, geometries with a low value of $\mathrm{n}$ show better heat transfer performance with gas mixtures.

Our conclusion that mixtures of noble gases do not give an overall enhancement in the performance of Stirling type machines contrasts with that drawn by Vanco [18] for Brayton power cycles. Vanco compares heat transfer and pressure drop at constant molecular weight (for example, performance with pure argon versus performance with a helium-xenon mixture of the same molecular weight) and finds enhanced heat transfer with no change in pressure drop. We, in contrast, compare systems at constant molar density and constant pressure.

Because the pressure rise per stage in turbo machinery is proportional to the density, constant molecular weight maintains a constant gross power output in a Brayton cycle with turbines. With reciprocating compressors and expanders such as in Stirling machines, however, the pressure rise is independent of density--depending only on the geometry of the machine--and constant molar density, not constant molecular weight, maintains constant gross refrigeration.

of all the noble gases, helium has both the lowest density, which gives the lowest pressure drop, and the highest thermal conductivity, which gives the best heat transfer. Adding heavier species always increases pressure drop with little or no improvement in the heat transfer.

Cryocoolers with turbo compressors might benefit from the use of mixtures for the working fluid because of the resulting reduction in the number of stages in the compressor. Of course, the dew point of the mixture needs to lie below the refrigeration temperature. 


\section{Nomenclature}

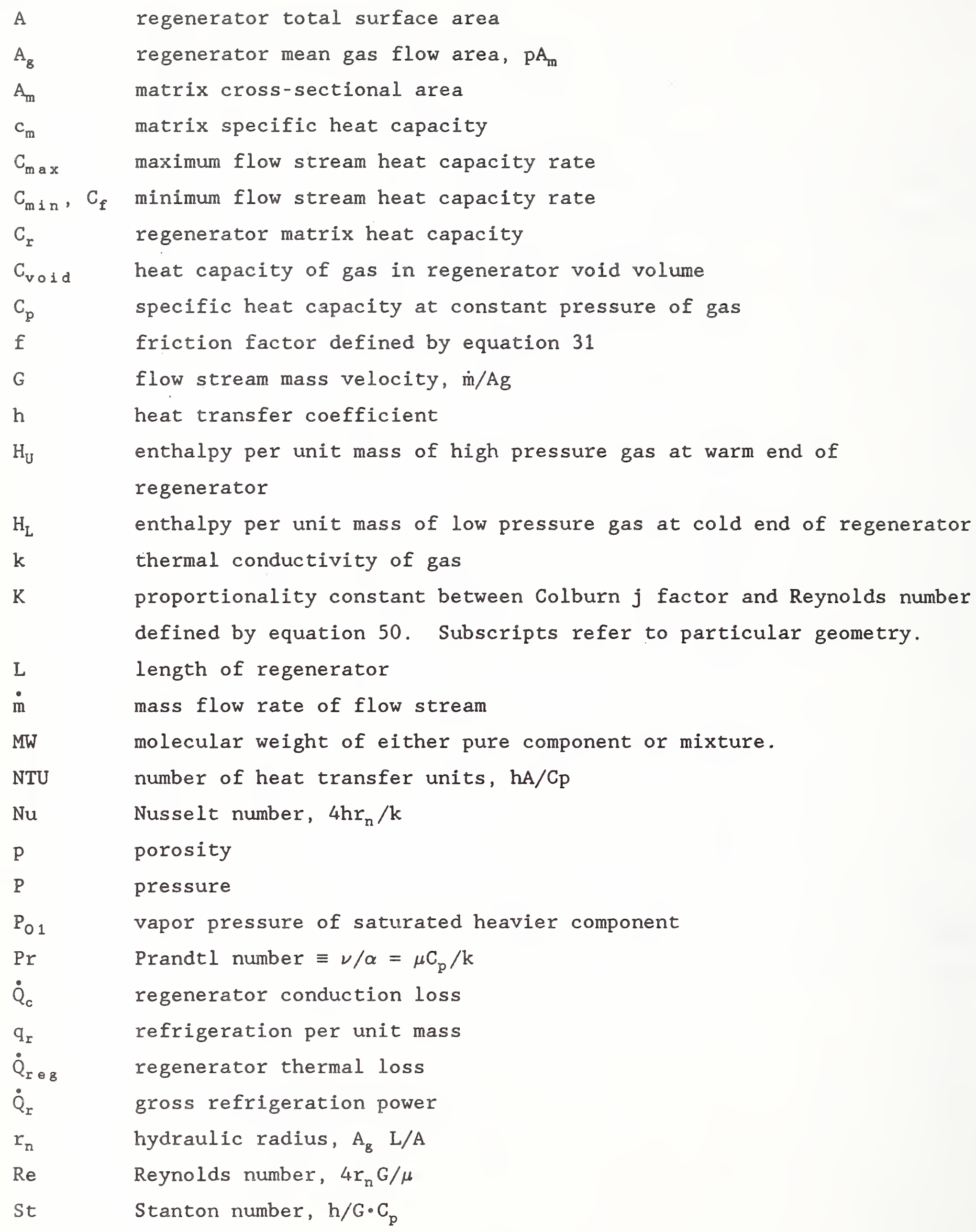

A

$\mathrm{A}_{\mathrm{g}}$

$A_{m}$

$\mathrm{c}_{\mathrm{m}}$

$\mathrm{C}_{\mathrm{max}}$

$\mathrm{C}_{\mathrm{min}}, \mathrm{C}_{\mathrm{f}}$

$\mathrm{C}_{\mathrm{r}}$

$\mathrm{C}_{\mathrm{vold}}$

$\mathrm{C}_{\mathrm{p}}$

f

G

h

$\mathrm{H}_{\mathrm{U}}$

$\mathrm{H}_{\mathrm{L}}$

k

K

L

m

MW

NTU

$\mathrm{Nu}$

p

P

$\mathrm{P}_{01}$

$\mathrm{Pr}$

$\dot{\mathrm{Q}}_{\mathrm{c}}$

$q_{r}$

$\dot{\mathrm{Q}}_{\mathrm{r} \theta \mathrm{B}}$

$\dot{\mathrm{Q}}_{\mathrm{r}}$

$r_{n}$

$\operatorname{Re}$

St

regenerator total surface area regenerator mean gas flow area, $\mathrm{PA}_{\mathrm{m}}$ matrix cross-sectional area matrix specific heat capacity maximum flow stream heat capacity rate minimum flow stream heat capacity rate regenerator matrix heat capacity heat capacity of gas in regenerator void volume specific heat capacity at constant pressure of gas friction factor defined by equation 31 flow stream mass velocity, $\dot{\mathrm{m}} / \mathrm{Ag}$ heat transfer coefficient enthalpy per unit mass of high pressure gas at warm end of regenerator enthalpy per unit mass of low pressure gas at cold end of regenerator thermal conductivity of gas proportionality constant between Colburn $j$ factor and Reynolds number defined by equation 50. Subscripts refer to particular geometry. length of regenerator mass flow rate of flow stream molecular weight of either pure component or mixture. number of heat transfer units, hA/Cp

Nusselt number, $4 h r_{n} / \mathrm{k}$

porosity

pressure

vapor pressure of saturated heavier component

Prandtl number $\equiv \nu / \alpha=\mu \mathrm{C}_{\mathrm{p}} / \mathrm{k}$

regenerator conduction loss

refrigeration per unit mass

regenerator thermal loss

gross refrigeration power

hydraulic radius, $A_{g} L / A$

Reynolds number, $4 r_{n} G / \mu$

Stanton number, $h / G \cdot C_{p}$ 
temperature

flow stream velocity

V. maximum expansion space volume

$\mathrm{V}_{\mathrm{r}}$ regenerator void volume

$\mathrm{x}_{1}$ mole fraction of lighter component of mixture

$\mathrm{y}_{1}, \mathrm{y}_{2} \quad$ transport properties of pure lighter and heavier components

\section{Greek}

$\alpha \quad$ thermal diffusivity; proportionality constant for modified Colburn analogy, equation 31

$\delta$ momentum boundary layer thickness

$\delta_{\text {I }} \quad$ thermal boundary layer thickness

$\epsilon$ regenerator effectiveness

$\mu \quad$ viscosity

$v \quad$ kinematic viscosity

$\rho$ density

$\rho_{\mathrm{m}}$ matrix density

$\rho_{M}$ molar density

$\phi$ enhancement factor, defined by equation 5

$\omega \quad$ cycle frequency 
[1] Rohsenow, W.M. and Choi, H. Heat, Mass, and Momentum Transfer, Englewood Cliffs, N.J., Prentice-Hall, Inc., 1961.

[2] Ely, J.F., Private communication.

[3] Ibele, W., Thermophysical properties, Handbook of Heat Transfer, W.M. Rohsenow and J.P. Hartnett, eds., New York, McGraw Hill, 1973.

[4] Brokaw, R.S., Approximate Formulas for Viscosity and Thermal Conductivity of Gas Mixtures, NASA TN D-2502, 1964.

[5] Stephan, K. and Heckenberger, T., Thermal Conductivity and Viscosity Data of Fluid Mixtures, DECHEMA Deutsche Gesellschaft fur Chemisches Apparatewesen, Chemische Technik und Biotechnologie e.V., Frankfurt/Main, 1988.

[6] Mullins, J.C. and Ziegler, W.T., Phase Equilibria in the Argon-Helium and Argon-Hydrogen systems from $68^{\circ}$ to $108^{\circ} \mathrm{K}$ and Pressures to 120

Atmospheres, International Advances in Cryogenic Engineering, K.D.

Timmerhaus, Editor, New York, 171-181, 1965.

[7] Kate, F.H., A Study of Solid-Vapor Equilibrium in the Helium-Krypton and Helium-Xenon Systems, Ph.D. Thesis, Stillwater, Oklahoma, Oklahoma State University, 1972.

[8] Kays, W.M. and London, A.L., Compact Heat Exchangers, 3rd ed., New York, M.cGraw-Hill, 1984.

[9] Pohlhausen, E., Z. Angew, Math. u. Mech., 1, 115, 1921.

[10] Eckert, E.R.G. and Drake, R.M., Jr., Heat and Mass Transfer, 2nd ed., New York, McGraw-Hill, 1959.

[11] Zukauskas, A., Heat Transfer in Turbulent Flows of Various Fluids, Turbulent Forced Convection in Channels and Bundles, S. Kakai and D.B. Spalding, eds., New York, Hemisphere Publishing Corp., 547-561, 1979.

[12] Pickett, P.E., Taylor, M.F., and McEligot, D.M., Heated Turbulent Flow of Helium-Argon Mixtures in Tubes, Int. J. Heat Mass Transfer, 22, 705 (1979).

[13] Kays, W.M., Convective Heat and Mass Transfer, New York, McGraw-Hill (1966).

[14] McAdams, W.H., Heat Transmission, 3rd ed., New York, McGraw-Hill (1954).

[15] Radebaugh, R. and Louie, B., A simple, first step to optimization of regenerator geometry, Proc. Third Cryocooler Conf., NBS Special

Publication 698, 177-196, 1983. 
[16] Arp, V. and Radebaugh, Interactive Program for Microcomputers to Calculate the Optimum Regenerator Geometry for Cryocoolers (REGEN and REGEN2), AFWAL-TR-87-3040, 1987.

[17] Colburn, A.P., Trans. Am. Inst. Chem. Engrs., 29, 174, 1933.

[18] Vanco, M.R., Analytical Comparison of Relative Heat-Transfer Coefficients and Pressure Drops of Inert Gases and Their Binary Mixtures, NASA TN D$2677,1964$. 

NBS-114A (REV. 2-8C)

U.S. DEPT. OF COMM.

BIBLIOGRAPHIC DATA

SHEET (See instructions)

1. PUBLICATION OR REPORT NO.

NISTIR $90-3936$
2. Performing Organ. Report No.1 3. Publication Date

September 1990

4. TITLE AND SUBTITLE

Effect of Noble Gas Mixtures on the Performance of Regenerative Type

Cryocoolers--Analytical Estimate

5. $\operatorname{AUTHOR}(S)$

David E. Daney

6. PERFORMING ORGANIZATION (If joint or other than NBS, see instructions)

U.S. DEPARTMENT OF COMMERCE

MATIONAL INSTITUTE OF STANDARDS AND TECHNOLOCY

BOULDER, COLORADO $80303-3328$

7. Contract/Grant No.

8. Type of Report \& Period Covered

9. SPONSORING ORGANIZATION NAME AND COMPLETE ADDRESS (Street, City, Stote, ZIP)

Air Force Space Technology Center

Kirtland Air Force Base, New Mexico 87117-6008

10. SUPPLEMENTARY NOTES

Document describes a computer program; SF-185, FIPS Software Summary, is attached.

11. ABSTRACT (A 200-word or less foctual summary of most significant information. If document includes a significant bibliogrophy or literature survey. mention it here)

We compare the performance of regenerators that use noble gas mixtures to the performance of those that use pure helium gas. Both helium-argon and helium-krypton mixtures are investigated. For some heat transfer surfaces, a modest gain in heat transfer can be achieved with these mixtures. The concomitant increase in pressure drop, however, more than offsets the heat transfer gain so the net regenerator loss increases for all cases we evaluated.

The dependence of heat transfer on Prandtl number has not been measured for the range associated with noble gas mixtures, $0.2<\operatorname{Pr}<0.5$, and we estimate that the uncertainty from this source can exceed 20 percent. We give our own estimates for the transport properties (Prandtl number, viscosity, and thermal conductivity) of helium-argon and helium-krypton mixtures because of the absence of experimental data at low temperature.

12. KEY WORDS (Six to twelve entries; alphabetical order; capitalize only proper names; and separate key words by semicolons) cryocoolers; gas mixtures; heat exchangers; heat transfer; noble gas mixtures; Prandt1 number; regenerators; thermal regenerators

13. AVAILABILITY

[x] Unlimited

For Official Distribution. Do Not Release to NTIS

Order From Superintendent of Documents, U.S. Government Printing Office, Washington, D.C. 20402.

X] Order From National Technical Information Service (NTIS), Springfield, VA. 22161
14. NO. OF

PRINTED PAGES

40

15. Price 

